\title{
Development and Validation of RP-HPLC Method for Estimation of Montelukast Sodium and Fexofenadine Hydrochloride in Pharmaceutical Preparations
}

\author{
M. KALYANKAR TUKARAM ${ }^{\mathrm{a}^{*}}$, R. WALE RISHA ${ }^{\mathrm{a}}$ and B. KAKDE RAJENDRA ${ }^{\mathrm{b}}$

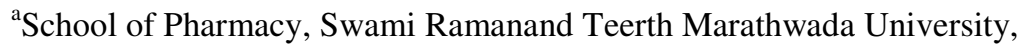 \\ Nanded-431606 (MS) India \\ ${ }^{\mathrm{b}}$ University Deptt. of Pharmaceutical Sciences, Rashtrasant Tukadoji Maharaj Nagpur \\ University, Campus, Nagpur-440033, MS, India \\ dr.kalyankartm@gmail.com
}

Received 23 August 2012 / Accepted 19 September 2012

\begin{abstract}
Objective of the present work was to develop a simple and precise HPLC method for montelukast sodium (MON) and fexofenadine hydrochloride (FEX). The combination is used as anti-asthmatic, anti-allergic and is available in tablet dosage form. HPLC separation was achieved with a hypersil ODS-C18 (5 $\mu, 250 \mathrm{~mm} \times 4.6 \mathrm{~mm}$, i.d.) as a stationary phase and methanol: acetonitrile: $1 \%$ trifluoroacetic acid $(80: 10: 10 \mathrm{v} / \mathrm{v} / \mathrm{v})$ as eluent, at a flow rate of $1.0 \mathrm{~mL} / \mathrm{min}$, UV detection was performed at $210 \mathrm{~nm}$. The retention time of montelukast sodium and fexofenadine hydrochloride were found to be 5.1 and 3.7 min respectively. Results of analysis were validated by recovery studies. Result of studies showed that the proposed RP-HPLC method is simple, rapid, accurate and precise which can be used for the routine determination of montelukast sodium and fexofenadine hydrochloride in bulk and its pharmaceutical dosage form.
\end{abstract}

Keywords: Montelukast sodium, Fexofenadine hydrochloride, Recovery, Liquid chromatography, Validation

\section{Introduction}

Drug analysis plays an important role in drug development, manufacture and its therapeutic use. Number of drugs and drug formulations introduced into the market by pharmaceutical industries is increasing at an alarming rate. Almost half of all marketed drugs are combination preparations. Therefore it is essential to determine two or more drugs simultaneously. For estimation of drugs in pure and their dosage forms, HPLC method is chosen since this method is simple, sensitive and reproducible.

Novel combination of montelukast sodium (MON) and fexofenadine hydrochloride (FEX) is available as tablet dosage form in the ratio of 12:1 and is used in treatment of asthma. Chemically montelukast is $2-[1-[(R)-[3-[2(E)-(7-$ chloroquinolin-2-yl) vinyl $]$ phenyl $]-$ 
3-[2- (1-hydroxy-1-methylethyl) phenyl] propyl -sulfanylmethyl] cyclopropyl] acetic acid. Montelukast is a cysteinyl leukotriene receptor antagonist. It blocks the action of leukotriene D4 (and secondary ligands LTC4 and LTE4) on the cysteinyl leukotriene receptor CysLT ${ }_{1}$ in the lungs and bronchial tubes by binding to it and is being used in the treatment of asthma ${ }^{1,2}$. The recommended dosage of MON is $10 \mathrm{mg}$ per day. The structure of montelukast sodium is shown in Figure 1.

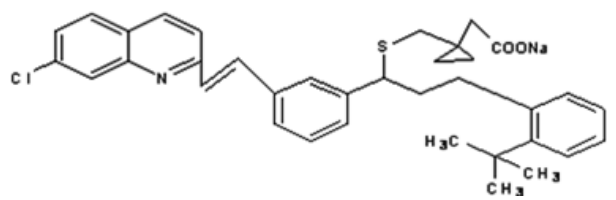

Figure 1. Structure of montelukast sodium

Chemically fexofenadine is (RS) - 2-[4-[1-hydroxy- 4-[4-(hydroxy- diphenyl- methyl) 1-piperidyl] butyl] phenyl] - 2-methyl- propanoic acid. Fexofenadine is a second-generation non-sedating selectively peripheral H1-blocker of the GI tract, large blood vessels and bronchial smooth muscle. Blockage prevents activation of the $\mathrm{H} 1$ receptors by histamine, preventing the symptoms associated with allergies from occurring. It is safer in treatment of asthma and urticaria ${ }^{3}$. The recommended dosage of FEX is $120 \mathrm{mg}$ per day. The structure of fexofenadine hydrochloride is shown in Figure 2.

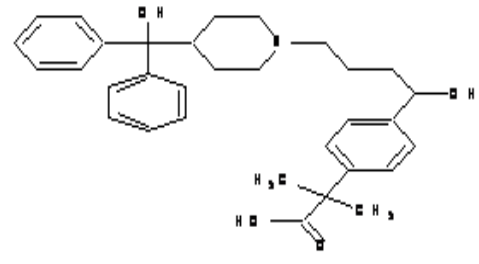

. $\mathrm{HCl}$

Figure 2. Structure of fexofenadine hydrochride

During literature survey it was found that, various HPLC methods have been estimated for the determination of montelukast sodium $^{4-7}$ and fexofenadine hydrochloride ${ }^{8-11}$ in combination with other drugs but no RP-HPLC method has been determined till date. Hence an attempt has been made to develop and validate a simple, economic, rapid and accurate method. The proposed method was validated according to ICH guidelines ${ }^{12,13}$.

The reported simple RP-HPLC method used methanol: acetonitrile: 1\% trifluoroacetic acid $(80: 10: 10 \mathrm{v} / \mathrm{v} / \mathrm{v})$ as a mobile phase. The goal of this study was to develop a method without using buffer in mobile phase, has less run time, and more sensitive compare to developed method for analysis of montelukast sodium and fexofenadine hydrochloride formulations, with extremely low LOD \& LOQ values.

\section{Experimental}

A HPLC (Perkin Elmer) method was developed using a Hypersil ODS-C18 (5 $\mu, 250 \mathrm{~mm} x$ $4.6 \mathrm{~mm}$, i.d.) with a PDA detector. The injection volume of $10 \mu \mathrm{L}$ was used throughout the analysis. Data were acquired and analyzed by Total Chrome software. The tablet "Montemac-FX" with $10 \mathrm{mg}$ of Montelukast sodium and $120 \mathrm{mg}$ of fexofenadine hydrochloride was manufactured by Macleods Pharmaceutical Ltd. Mumbai. India. All other reagents used were of HPLC grade. 


\section{Method development and optimization}

The standard solutions containing montelukast sodium and fexofenadine hydrochloride were run and combinations of solvents were tried to get a good separation and stable peak. From various mobile phases tried it was found that mobile phase containing methanol: acetonitrile: $1 \%$ trifluoroacetic acid with in ratio (80: 10:10 v/v/v) gives satisfactory result with sharp, well defined and resolved peaks with minimum tailing as compare to other mobile phases.

An adequate separation of both compounds was obtained using Hypersil ODS-C18 (5 $\mu$, $250 \mathrm{~mm} \times 4.6 \mathrm{~mm}$, i.d.) column with flow rate of $1 \mathrm{~mL} / \mathrm{min}$. A typical chromatogram of separation of two components is shown in Figure 3.

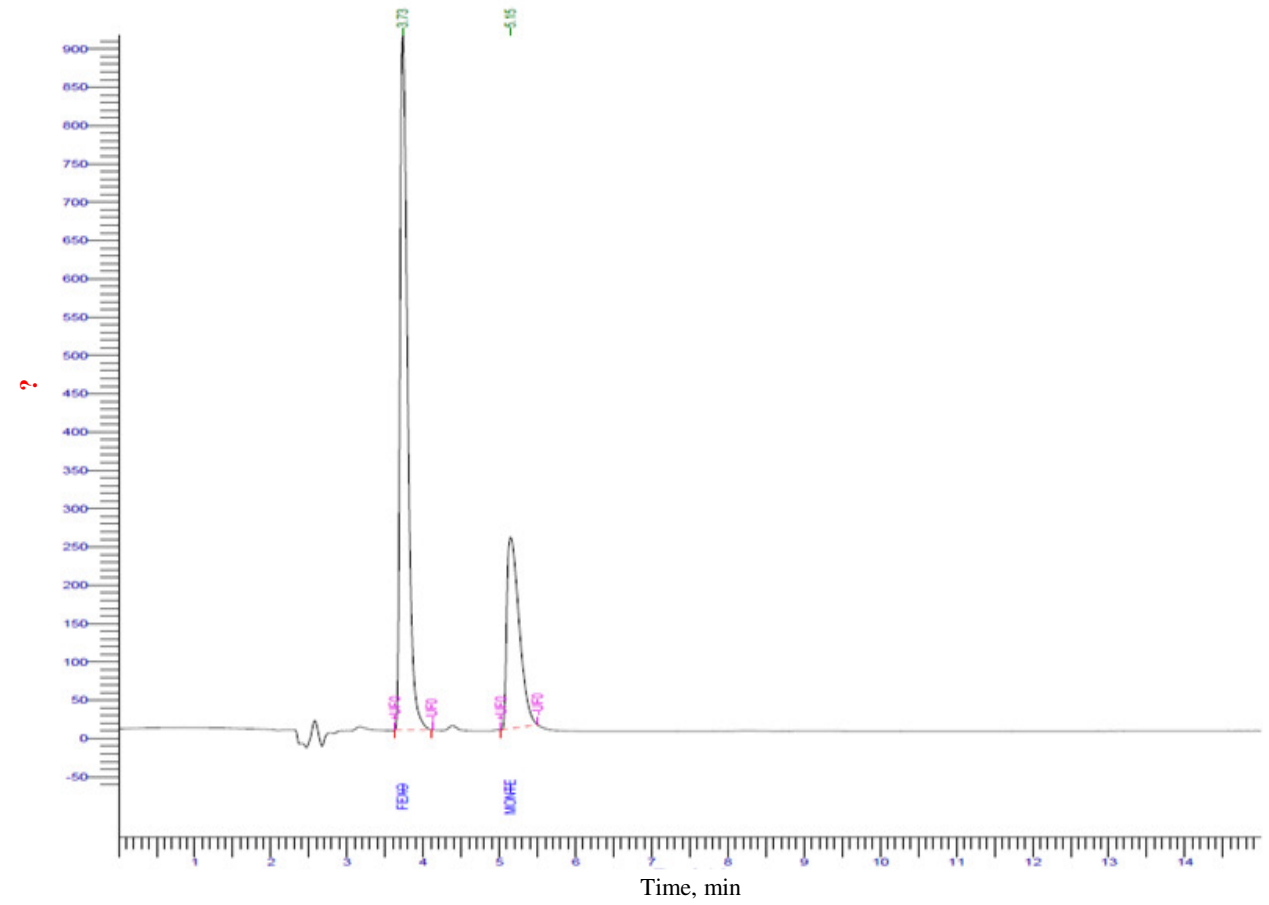

Figure 3. Chromatogram for montelukast sodium and fexofenadine hydrochloride

As montelukast sodium and fexofenadine hydrochloride exhibit significant absorbance at wavelength $210 \mathrm{~nm}$, it was selected as detection wavelength for simultaneous determination of montelukast sodium and fexofenadine hydrochloride in pharmaceutical dosage forms.

\section{Standard solution preparation}

\section{Montelukast sodium standard stock solution $(25 \mu \mathrm{g} / \mathrm{mL})$}

Accurately weighed $2.5 \mathrm{mg}$ of reference standard of montelukast sodium was transferred to $100 \mathrm{~mL}$ calibrated volumetric flask. About $25 \mathrm{~mL}$ of mobile phase was added and sonicated for $5 \mathrm{~min}$ to ensure complete solubilization. Then volume was made up to the mark with mobile phase to obtained standard stock solution $(25 \mu \mathrm{g} / \mathrm{mL})$ of drug and it was sonicated for $10 \mathrm{~min}$. Stock solution was filter through a $0.45 \mu \mathrm{m}$ membrane filter paper. 
Fexofenadine hydrochloride standard stock solution $(300 \mu \mathrm{g} / \mathrm{mL})$

Accurately weighed $15 \mathrm{mg}$ of reference standard of fexofenadine hydrochloride was transferred to $50 \mathrm{~mL}$ volumetric flask. About $25 \mathrm{~mL}$ of mobile phase was added, sonicated for 5 min to ensure complete solubilization and then volume was made up to the mark with mobile phase to obtained standard stock solution $(300 \mu \mathrm{g} / \mathrm{mL})$ of drug. Stock solution was sonicated for $10 \mathrm{~min}$ and filter through a $0.45 \mu \mathrm{m}$ membrane filter paper.

\section{Preparation of calibration curve of montelukast sodium and fexofenadine hydrochloride}

By appropriate dilution of the standard stock solution, different dilution were prepared to obtain concentration ranging from $2.5 \mu \mathrm{g} / \mathrm{mL}$ to $15 \mu \mathrm{g} / \mathrm{mL}$ for montelukast sodium and $30 \mu \mathrm{g} / \mathrm{mL}$ to $180 \mu \mathrm{g} / \mathrm{mL}$ for fexofenadine hydrochloride. From these solution $10 \mu \mathrm{L}$ injection of each concentration of drug were three times injected separately and chromatographs are plotted under the conditions as described earlier. The detector set at $210 \mathrm{~nm}$ and peak areas were recorded. The individual chromatograms of standard MON and FEX are shown in Figure 4 and 5. The standard calibration curve was plotted separately as peak area versus respective concentrations of MON and FEX. The linearity of both drug found in acceptable range.

Standard calibration data for MON and FEX are shown in Table 1,2 respectively. Standard equation for MON was found to be $y=14786 x+2478$, with correlation coefficient value of $r^{2}=0.998$ and the standard equation for FEX was found to be $y=24423 x-4261$ with correlation coefficient value of $r^{2}=0.999$.

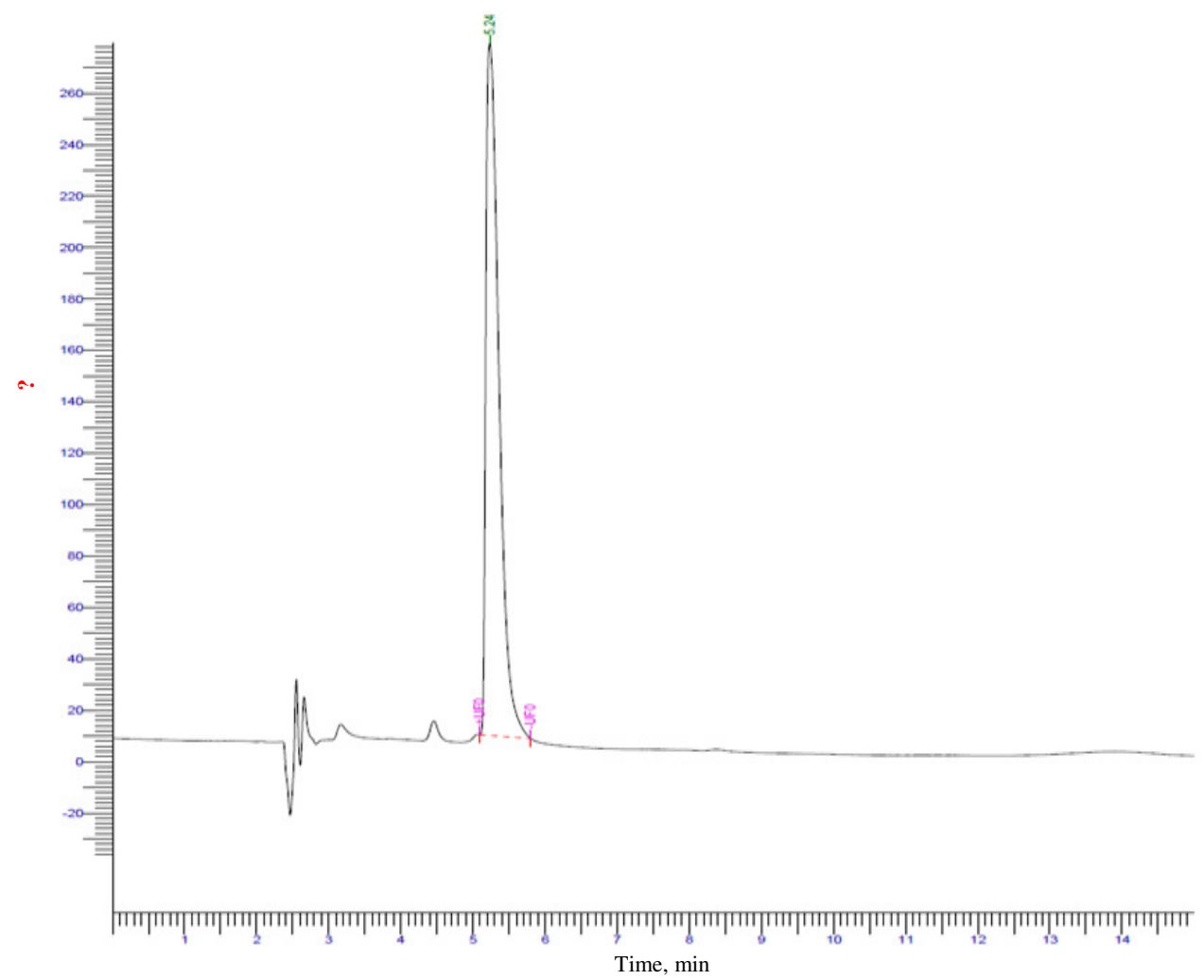

Figure 4. HPLC chromatogram of standard montelukast sodium 


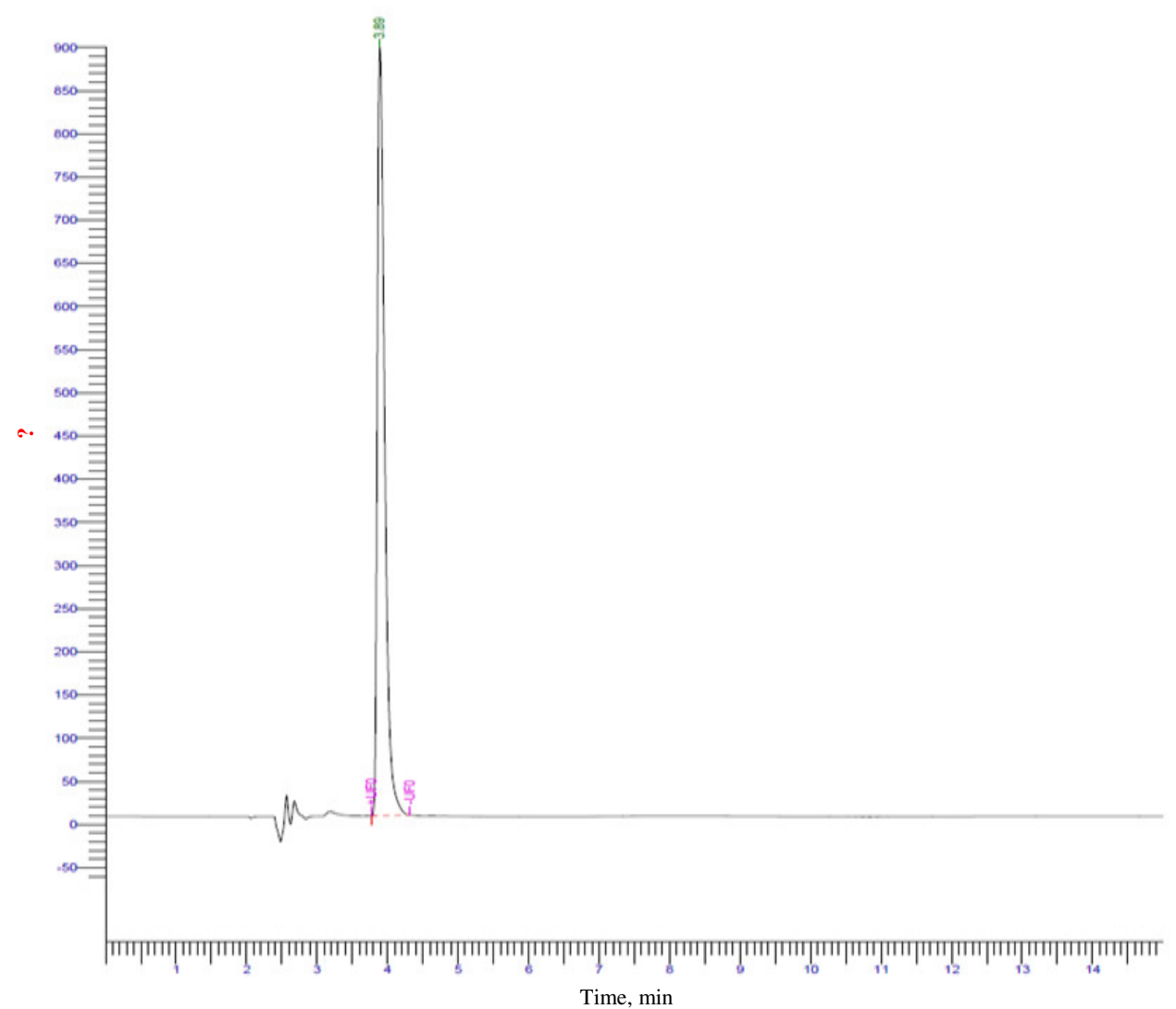

Figure 5. HPLC Chromatogram of Standard FEX

Table 1. Calibration table for MON

\begin{tabular}{ccc}
\hline S. No. & Concentration of $\mathrm{MON}, \mu \mathrm{g} / \mathrm{mL}$ & Area \\
\hline 1 & 2.5 & 38883 \\
2 & 5 & 76407 \\
3 & 7.5 & 115524 \\
4 & 10 & 156209 \\
5 & 12.5 & 186751 \\
6 & 15 & 219817 \\
\hline
\end{tabular}

Table 2. Calibration table for FEX

\begin{tabular}{ccc}
\hline S. No. & Concentration of FEX, $\mu \mathrm{g} / \mathrm{mL}$ & Area \\
\hline 1 & 30 & 653481 \\
2 & 60 & 1533347 \\
3 & 90 & 2226094 \\
4 & 120 & 2929784 \\
5 & 150 & 3616148 \\
6 & 180 & 4397887 \\
\hline
\end{tabular}




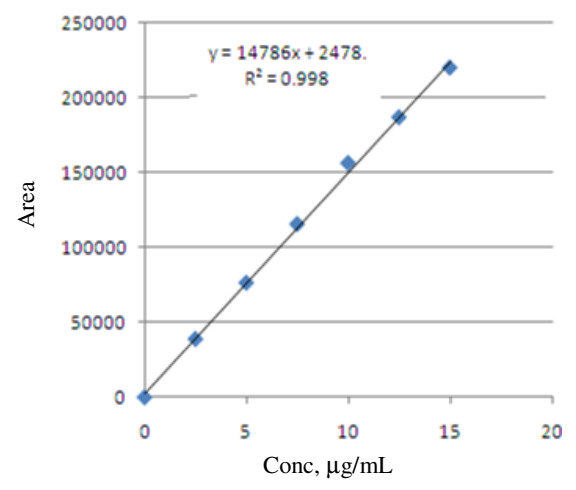

Figure 6. Calibration curve of standard MON

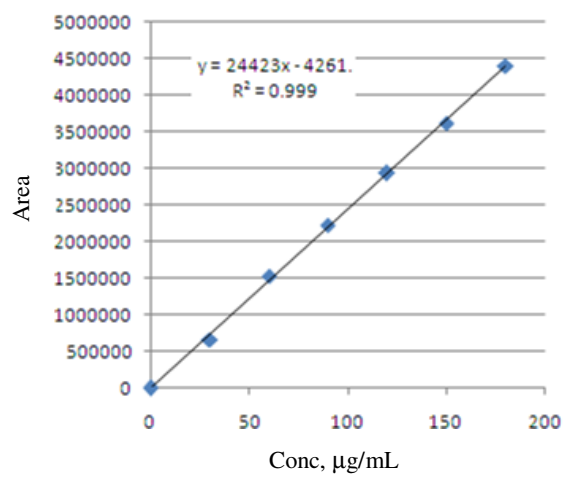

Figure 7. Calibration curve of standard FEX

\section{Analysis of marketed formulation}

Twenty tablets were weighed accurately and triturate to produce fine powder. A quantity equivalent to $10 \mathrm{mg}$ of MON and $120 \mathrm{mg}$ of FEX was weighed and transferred to $100 \mathrm{~mL}$ volumetric flask. $25 \mathrm{~mL}$ mobile phase was added it was sonicated for 5 mins and volume was made to $100 \mathrm{~mL}$ with mobile phase. Again sonicated for $10 \mathrm{mins}$ and filtered through $0.45 \mu \mathrm{m}$ membrane filter paper. By appropriate dilution of this solution with mobile phase a sample was obtained solution within the concentration range for two drugs. A $10 \mu \mathrm{L}$ volume of each sample solution was injected into HPLC system for six times under the chromatographic condition as stated above. The area of each peak was measure at $210 \mathrm{~nm}$.

\section{Validation procedure}

The method was validated for the parameters such as system suitability, specificity, linearity and range, accuracy, precision, ruggedness, and robustness. System suitability of the method was evaluated by analyzing the repeatability, peak symmetry (symmetry factor), theoretical plates of the column, resolution between the peaks, capacity factor and relative retention. Specificity was also determined in the presence of excipients used in formulation, and chromatogram was observed and compared with that of a standard peak. To evaluate linearity of the method, serial dilutions were made from a standard stock solution in the working range.

To determine accuracy of the method in dosage formulation, a working standard of a drug was prepared. Samples for recovery studies were prepared by spiking known amount of working standard at three concentration levels (80\%, 100\% and 120\%) and analyzed. The precision of the method was investigated with respect to repeatability. To determine intermediate precision, standard solutions of the drug at the $100 \%$ concentration level were analyzed three times within the same day (intra-day variation) and on three different days (interday variation). Robustness studies were performed on method precision by making slight variations in flow rate, amount of the mobile phase and $\mathrm{pH}$ changes.

\section{Results and Discussion}

Goal of this study was to develop a rapid, easy accurate, precise, reliable and least time consuming HPLC method for the analysis of from the combined pharmaceutical formulation. 
Newly developed method has been validated as per guidelines of the international conference on harmonization of Technical requirements for the registration of pharmaceutical for Human use [ICH 2005] and has recommended the accomplishment of specificity, linearity, precision, accuracy, ruggedness and robustness of the method.

\section{Specificity}

It is the ability of an analytical method to assess unequivocally the analyte of interest in the presence of components that may be expected to be present, such as impurities, degradation products and matrix components. The proposed method is quite selective. There was no other interfering peak around the retention time of montelukast sodium and fexofenadine hydrochloride; also the base line did not show any significant noise.

\section{Linearity}

The linearity of an analytical method is its ability to obtain test results in direct or well defined mathematical transformation proportional to the concentration of analyte in samples within a given range. It should be established across the range of analytical procedure. Linearity is generally represented as the correlation coefficient, the slope of regression line, etc. The results of linearity studies are given in Table 3.

Table 3. Linear regression data for calibration curve of MON and FEX

\begin{tabular}{ccccc}
\hline Drug & Linearity Range, $\mu \mathrm{g} / \mathrm{mL}$ & Slope & Intercept & $\begin{array}{c}\text { Regression } \\
\text { Coefficient }\end{array}$ \\
\hline MON & $2.5-15.0$ & 14786 & 2478 & 0.998 \\
FEX & $30-180$ & 24423 & 4261 & 0.999 \\
\hline
\end{tabular}

Analysis of MON and FEX in combined tablet dosage form

Different concentrations of tablet sample were prepared by serial dilution technique and concentration of $10 \mu \mathrm{g} / \mathrm{mL}$ of MON \& $120 \mu \mathrm{g} / \mathrm{mL}$ of FEX was used for analysis. The results of marketed formulation studies are given in Table 4.

Table 4. Result of tablet formulation

\begin{tabular}{cccccc}
\hline Drug & $\begin{array}{c}\text { Labeled amt., } \\
\text { mg* }\end{array}$ & $\begin{array}{c}\text { Estimated } \\
\text { amt., mg* }\end{array}$ & $\begin{array}{c}\% \\
\text { Estimation* }\end{array}$ & S.D.* & $\%$ RSD* \\
\hline MON & 10 & 9.959494 & 99.59 & 0.2861 & 0.2872 \\
FEX & 120 & 119.7117 & 99.75 & 0.2439 & 0.2444 \\
\hline \multicolumn{5}{c}{ *mean of six determinations }
\end{tabular}

\section{Precision}

Precision of the method was verified by using tablet stock solution. The repeatability indicates the performance of the HPLC instrument under chromatographic conditions. Intraday and interday precision was determined by repeating assay for six times in same day for intraday precision and on different day for interday precision Studies. The results of these analyses are shown in Table 5, 6 \& 7.

Table 5. Statistical validation of repeatability data

\begin{tabular}{cccc}
\hline Drug & Area* & S. D. * & R.S.D. * \\
\hline MON & 155742 & 0.3543 & 0.3543 \\
FEX & 2901700 & 0.3770 & 0.4130 \\
\hline
\end{tabular}

*Denotes average of 6 determination 
Table 6. Statistical validation of Intraday Precision data

\begin{tabular}{cccc}
\hline Drug & Mean* & S. D. ${ }^{*}$ & \%R.S.D. * \\
\hline MON & 99.93 & 0.393 & 0.393 \\
FEX & 99.97 & 0.322 & 0.334 \\
\hline \multicolumn{4}{c}{ *Denotes average of 6 determination }
\end{tabular}

Table 7. Statistical validation of interday precision data

\begin{tabular}{cccc}
\hline Drug & Mean $^{*}$ & S. D. * & \%R.S.D. * \\
\hline MON & 99.95 & 0.315 & 0.316 \\
FEX & 100.04 & 0.319 & 0.318 \\
\hline \multicolumn{4}{c}{ *Denotes average of 6 determination }
\end{tabular}

\section{Recovery studies}

The accuracy of the method was determined by calculating recoveries of MON and FEX by the standard addition method. Known amounts of standard solutions of MON and FEX were added at 80, 100 and $120 \%$ levels to pre quantified sample solutions of MON and FEX. The result of recovery study along with its statistical validation was shown in Table $8 \& 9$.

Table 8. Result of recovery study

\begin{tabular}{ccccccccc}
\hline $\begin{array}{c}\text { Level of } \\
\text { recovery }\end{array}$ & \multicolumn{2}{c}{$\begin{array}{c}\text { Amount } \\
\text { present, mg }\end{array}$} & \multicolumn{2}{c}{$\begin{array}{c}\text { Added conc. } \\
\text { mg }\end{array}$} & \multicolumn{2}{c}{$\begin{array}{c}\text { Total amount } \\
\text { recovered, mg }\end{array}$} & \multicolumn{2}{c}{ \% Recovery } \\
\hline \multirow{4}{*}{80} & MON & FEX & MON & FEX & MON & FEX & MON & FEX \\
& 10 & 120 & 8 & 96 & 17.93 & 215.98 & 99.60 & 99.99 \\
& 10 & 120 & 8 & 96 & 17.98 & 215.92 & 99.91 & 99.96 \\
\multirow{3}{*}{100} & 10 & 120 & 8 & 96 & 17.97 & 215.87 & 99.82 & 99.94 \\
& 10 & 120 & 10 & 120 & 19.97 & 239.98 & 100.00 & 99.99 \\
& 10 & 120 & 10 & 120 & 19.95 & 239.79 & 99.76 & 99.91 \\
120 & 10 & 120 & 10 & 120 & 19.98 & 239.83 & 99.88 & 99.22 \\
& 10 & 120 & 12 & 144 & 21.97 & 263.87 & 99.85 & 99.52 \\
& 10 & 120 & 12 & 144 & 21.98 & 263.66 & 99.89 & 99.87 \\
& 10 & 120 & 12 & 144 & 21.99 & 263.96 & 99.96 & 99.98 \\
\hline
\end{tabular}

Table 9. Statistical validation of recovery study

\begin{tabular}{ccccccc}
\hline $\begin{array}{c}\text { Level of } \% \\
\text { recovery }\end{array}$ & \multicolumn{2}{c}{$\%$ Mean recovery* } & \multicolumn{2}{c}{ S.D. * } & \multicolumn{2}{c}{$\%$ R.S.D. * } \\
\hline & MON & FEX & MON & FEX & MON & FEX \\
80 & 99.78 & 99.97 & 0.161 & 0.029 & 0.162 & 0.029 \\
100 & 99.83 & 99.94 & 0.061 & 0.043 & 0.061 & 0.043 \\
120 & 99.90 & 99.94 & 0.056 & 0.057 & 0.056 & 0.057 \\
\hline
\end{tabular}

\section{$L O D \& L O Q$}

*Denotes average of 6 determination

The detection limit of an individual analytical procedure is lowest amount of analyte in a sample that can be detected but not necessarily quantitated as an exact value. The quantitation limit of an individual analytical procedure is the lowest amount of analyte in a sample that can be quantitatively determined with suitable precision and accuracy. In order to estimate the limit of detection (LOD) and limit of quantitation (LOQ), the signal-to-noise ratio $(\mathrm{S} / \mathrm{N})$ of 3 and 10 was determined for six replicate determinations. 
LOD and LOQ were 0.000265 and 0.000785 respectively for MON and 0.000177 and 0.000517 respectively for FEX, pointed towards adequate sensitivity of the method.

\section{Robustness of the method}

The robustness of an analytical procedure is a measure of its capacity to remain unaffected by small, but deliberate variations in method parameters and provides an indication of its reliability during normal usage.

To evaluate the robustness of the method, deliberate variation were made in method parameter such as, change in flow rate, $\mathrm{pH}$ of the buffer, column temperature and ratio of mobile phase. The results are shown in Tables $10(\mathrm{a}-\mathrm{d})$. To ascertain resolution and reproducibility of the chromatographic system, system suitability parameters were studied (Table 11) and summary of validation parameters of proposed method are given in Table 12.

Table 10. Robustness testing; (a) Flow rate ( $\mathrm{mL} / \mathrm{min}$ )

\begin{tabular}{ccccccccr}
\hline \multirow{2}{*}{$\begin{array}{c}\text { Flow rate } \\
\text { mL/min }\end{array}$} & \multicolumn{2}{c}{ Retention time* } & \multicolumn{2}{c}{$\begin{array}{c}\text { Tailing } \\
\text { factor* }\end{array}$} & \multicolumn{2}{c}{ Peak area* } & \multicolumn{2}{c}{$\begin{array}{c}\text { \% Content } \\
\text { found* }\end{array}$} \\
\cline { 2 - 9 } & MON & FEX & MON & FEX & MON & FEX & MON & FEX \\
\hline 0.8 & 6.578 & 4.767 & 1.60 & 1.51 & 158951 & 294543 & 100.62 & 99.33 \\
1 & 5.147 & 3.731 & 1.61 & 1.50 & 158548 & 294108 & 99.37 & 99.33 \\
1.2 & 4.4 & 3.146 & 1.62 & 1.49 & 157890 & 294817 & 99.38 & 100.67 \\
Mean \pm S.D. 5.375 1.107 & $3.881 \pm 0.821$ & 1.61 & 1.5 & 158463 & 294489 & 99.79 & 99.77 \\
\hline
\end{tabular}

(b) $\mathrm{pH}$ of buffer

\begin{tabular}{ccccccccc}
\hline \multirow{2}{*}{$\mathrm{pH}$} & \multicolumn{2}{c}{ Retention time* } & \multicolumn{2}{c}{$\begin{array}{c}\text { Tailing } \\
\text { factor* }\end{array}$} & \multicolumn{2}{c}{ Peak Area* } & \multicolumn{2}{c}{$\begin{array}{c}\text { \% Content } \\
\text { found* }\end{array}$} \\
\cline { 2 - 9 } & MON & FEX & MON & FEX & MON & FEX & MON & FEX \\
\hline 3.3 & 6.959 & 3.730 & 1.59 & 1.51 & 158549 & 294840 & 99.37 & 99.33 \\
3.5 & 5.147 & 3.731 & 1.58 & 1.50 & 158143 & 294009 & 100.63 & 100.66 \\
3.7 & 6.813 & 4.121 & 1.59 & 1.51 & 159087 & 295120 & 99.37 & 99.33 \\
Mean \pm S.D. 6.306 \pm 1.007 & $3.861 \pm 0.225$ & 1.58 & 1.50 & 158593 & 294656 & 99.79 & 99.77 \\
\hline
\end{tabular}

(c) Column temperature

\begin{tabular}{cccccccccc}
\hline \multirow{2}{*}{ Temp. ${ }^{0} \mathrm{C}$} & \multicolumn{2}{c}{ Retention time* } & \multicolumn{2}{c}{ Tailing factor* } & \multicolumn{2}{c}{ Peak Area* } & \multicolumn{2}{c}{$\begin{array}{c}\% \text { Content } \\
\text { found* }\end{array}$} \\
\cline { 2 - 10 } & MON & FEX & MON & FEX & MON & FEX & MON & FEX \\
\hline 23 & 3.916 & 3.894 & 1.61 & 1.5 & 157952 & 294630 & 99.37 & 100.00 \\
25 & 5.147 & 3.731 & 1.60 & 1.50 & 150148 & 293901 & 99.31 & 99.33 \\
27 & 3.901 & 3.879 & 1.59 & 1.49 & 151597 & 294112 & 100.62 & 100.67 \\
Mean \pm S.D. & $4.321 \pm 0.715$ & $3.835 \pm 0.090$ & 1.6 & 1.49 & 153232 & 294214 & 99.76 & 100.00 \\
\hline
\end{tabular}

(d) Ratio of mobile phase

\begin{tabular}{ccccccccc}
\hline \multirow{2}{*}{ Ratio } & \multicolumn{2}{c}{ Retention time* } & \multicolumn{2}{c}{$\begin{array}{c}\text { Tailing } \\
\text { factor * }\end{array}$} & \multicolumn{2}{c}{ Peak Area* } & \multicolumn{2}{c}{$\begin{array}{c}\text { Content } \\
\text { found* }\end{array}$} \\
\cline { 2 - 10 } & MON & FEX & MON & FEX & MON & FEX & MON & FEX \\
\hline $78: 12: 10$ & 6.805 & 3.909 & 1.61 & 1.56 & 157549 & 295141 & 99.37 & 99.35 \\
$80: 10: 10$ & 5.147 & 3.731 & 1.60 & 1.55 & 158543 & 294311 & 99.37 & 99.35 \\
$82: 08: 10$ & 6.560 & 3.147 & 1.59 & 1.54 & 159072 & 294815 & 100.62 & 100.64 \\
Mean \pm S.D. & $6.171 \pm 0.895$ & $3.596 \pm 0.399$ & 1.6 & 1.55 & 158388 & 294755 & 99.78 & 99.78 \\
\hline
\end{tabular}

*Denotes average of 3 determination 
Table 11. Study of system suitability parameter

\begin{tabular}{cccc}
\hline Sr. No. & Parameters & MON & FEX \\
\hline 1 & Retention time, min & 5.147 & 3.731 \\
2 & Resolution & \multicolumn{2}{c}{6.215} \\
3 & Asymmetry factor & 1.67 & 1.56 \\
4 & Theoretical plate & 15471.85 & 17083.10 \\
\hline
\end{tabular}

Table 12. Summary of validation parameters of proposed method

\begin{tabular}{lcc}
\hline \multicolumn{1}{c}{ Parameters } & MON & Observation \\
& $2.5-15$ & FEX \\
\hline Linearity range, $\mu \mathrm{g} / \mathrm{mL}$ & 0.998 & 0.999 \\
Correlation coefficient & $\mathrm{y}=14786 \mathrm{x}+2478$ & $\mathrm{y}=24423 \mathrm{x}-4261$ \\
Regression equation & 0.000265 & 0.000177 \\
$\mathrm{LOD}, \mu \mathrm{g} / \mathrm{mL}$ & 0.000785 & 0.000517 \\
$\mathrm{LOQ}, \mu \mathrm{g} / \mathrm{mL}$ & Robust & Robust \\
Robustness & & \\
Precision (R.S.D.) & 0.393 & 0.334 \\
Intraday (n=6) & 0.316 & 0.318 \\
Interday (n=6) & $99.84 \%$ & $99.95 \%$ \\
$\%$ Recovery(n=3) & & \\
\hline
\end{tabular}

\section{Conclusion}

It is a well known that the validation procedure is an integral part of the analytical method development. Therefore, the developed method was validated according to the ICH guidelines Q2 (R1). Based on the results, it can be concluded that above developed RPHPLC method is suitable for estimation of montelukast sodium and fexofenadine Hydrochloride in tablet formulation. Hence this method can be used in quality control for routine analysis of the finish product.

\section{Acknowledgment}

Authors overwhelmingly acknowledge the services provided by our mentor, School of Pharmacy, SRTMU, Nanded. Moreover I am deeply indebted to Dr. S.G Gattani for his keen interest, all time moral support and suggestions in further improvement of my work.

\section{References}

1. Rashmitha N, Sunder T J, Srinivas C H, Srinivas N, Ray U K and Sharma H K, J Chem., 2010, 7, 555-563.

2. Singh R M, Saini P K, Mathur S C, Singh G N and Lal B, Indian J Pharm Sci., 2010, 72(2), 235-237.

3. Narayana B and Veena K, Indian J Chem Technol., 2010, 17(5), 386-390.

4. Ashokkumar S, Senthilraja M and Perumal P, Int J Pharm Res., 2009, 1(4), 8-12.

5. Sane R T, Menezes A, Mote M and Moghe A Gundi G, J Planar Chromatogr., 2004, 17, 75-78.

6. Patil S, Pore Y V, Kuchekar B S, Mane A and Khire V G, Indian J Pharm Sci., 2009, 71(1), 58-61.

7. Radhakrishna T, Narasaraju A, Ramakrishna and Satyanarayana A, J Pharm Biomed Anal., 2003, 31, 359-368. 
8. Sevgi Karakuş, İlkay Küçükgüzel and Güniz Küçükgüzel Ş, J Pharm Biomed Anal., 2008, 46(2), 295-302.

9. Arayne M S, Sultana N, Mirza A Z and Siddiqui F A, J Chromatogr Sci., 2010, 48, 382-385.

10. Naoe Yamanea, Zenzaburou Tozuka, Yuichi Sugiyama, Toshiko Tanimoto, Akira Yamazaki and Yuji Kumagai, J Chromatogr B, 2007, 858(1-2), 118-128.

11. Pattana S, Bungon K and Aurasorn S, J Chromatogr B, 2008, 869(1-2), 38-44.

12. ICH, Q2A Validation of Analytical Procedures: Consensus Guidelines; ICH Harmonized Tripartite Guidelines, 1994.

13. ICH, Q2B Validation of Analytical Procedures: Methodology, Consensus, Consensus Guidelines; ICH Harmonized Tripartite Guidelines, 1996. 